\title{
Detection of Most Pathogenic Bacteria in Renal Failure and Urinary Tract Infections Patients with Antibiotics Patterns
}

\author{
Jafar Jumaa Hassooni ${ }^{1}$, Jabbar Jasim Kareem ${ }^{2}$, Maysoon Mohammed Hassan ${ }^{1}$, \\ Abbas Naser Rashid ${ }^{3}$ \\ ${ }^{1}$ Department ob Basic Science, College of Dentistry, University of Wassit, Kut City, Iraq \\ ${ }^{2}$ Department ob Tooth Industry, College of Dentistry, University of Wassit, Kut City, Iraq \\ ${ }^{3}$ Laboratory Center, Health Center of Wassit, Kut City, Iraq
}

Email address:

physian16@gmail.com (J. J. Hassooni)

\section{To cite this article:}

Jafar Jumaa Hassooni, Jabbar Jasim Kareem, Maysoon Mohammed Hassan, Abbas Naser Rashid. Detection of Most Pathogenic Bacteria in Renal Failure and Urinary Tract Infections Patients with Antibiotics Patterns. International Journal of Biomedical Engineering and Clinical Science. Vol. 4, No. 1, 2018, pp. 15-20. doi: 10.11648/j.ijbecs.20180401.13

Received: October 6, 2017; Accepted: January 18, 2018; Published: February 11, 2018

\begin{abstract}
Urinary tract infection (UTIs) are some of the most common infections experienced by humans and most common cause of both community and nosoncomial infection for patients admitted to hospitals in worldwide. To shed light on this subject, present study was done to investigate relationship between bacterial infection and renal failure after treatment by follow up general urine examination, blood urea and serum creatinine. Two hundred and thirty samples has been taken from individuals their ages between ( 2 to 70 ) years old males and females these included one hundred and five urine samples from females and one hundred and twenty five urine samples from males. Samples has been tested by general urine examination by microscope and by chemical tested by (Strip urine-uorscan) by using number of chemical factors like (S. siliva celicielic acid, Benedict, Barium chloride Bacl, Ehrlich's, Foshus), also culture and antibiotics sensitivity test was done. Results of general urine examination appears two hundred and twenty two suffer from urinary tract infection percent $96.5 \%$ and 8 only with no urinary tract infection in $3.45 \%$ percent from urine samples. It has been taken two hundred and twenty two blood Samples from individuals who has urinary tract infection then detected (Blood urea, serum creatinine and urine sugar tests) to know relationship between bacterial infections and renal failure. Also in this study detected different types of bacteria pathogens in which isolated from patients with urinary tract infection with or without renal failure, Serotyping and antibiotics sensitivity test also done to known more suitable drug for each pathogens and antibiotic resistance.
\end{abstract}

Keywords: Urinary Tract Infections, Renal Failure, Escherichia coli

\section{Introduction}

Urinary tract infection are some of the most common infections experienced by humans, exceeded in frequency among ambulatory patients by respiratory and gastrointestinal infections indeed bacterial infections of the urinary tract are the most common cause of both community acquired and nosoncomial infection for patient admitted to hospitals in the united states the prognosis and management at UTLS however depend on the site of infection and any predis posing factors [1].

Urinary tract infection are serious health problem affecting millions of people each year million in the united state alone and it was the second most common type of infection more frequently in women than in men furthermore approximately $20 \%$ of women who recurrence [2].

Urinary tract infection are relatively easy to diagnose A clean cache urine specimen is used and urine determine the presence of a high level of white blood cells which may indicate a bacteria may then be cultured to determine the type of bacteria and susceptibility test par antibiotic should be used to treat the infection.

However urinary tract infections also account for up to $40 \%$ of nasocomail infections catheters these hospitalacquired infections tend to be more serious because the bacteria resistant to drug treatment and patients are often in poor general health [3].

Urinary tract infection account for more than 7 million 
visits to physicians offices french epidemiologic study evaluated is annual incidence at 53000 diagnoses per million per year which represent to $1.05 \%$ to $2.10 \%$ of the activity of general practitioners in females was estimated to be 250000

The incidence of urinary tract infection is higher among females in who it commonly accurse in an anatomically normal urinary tract conversely in males and children [4].

\section{Materials and Methods}

The following instruments were used throughout the study

Table 1. Devices and materials.

\begin{tabular}{lll}
\hline No. & Name of Instrument & Company (origin) \\
\hline 1. & Centrifuge & Elite-Medium \\
2. & Autoclave & Portable \\
3. & Balance & Metler (Switzerland) \\
4. & Distillator & Alab tech-(Korea) \\
5. & Electric Oven & Binder (Germany) \\
6. & Incubator Bacteriology & Binder (Germany) \\
7. & Sensitive electronic balance & Denver \\
8. & Shaker incubator & Binder (Germany) \\
9. & Microscope & Olympus (Japan) \\
10. & Spectrophotometer & Shimadzu (Japan) \\
11. & Water bath & Tefea- Hannover (Germany) \\
12. & Micropipettes (different size) & Gilson (france) \\
13. & Magnetic Stirrer & Japan \\
14. & Vortex mixer & Portable \\
15. & Refrigerator & Japan \\
16. & Inverted Microscope & Olympus (Japan) \\
17. & Freeze (-20C ${ }^{\circ}$ ) & Bender (Germany) \\
18. & Co2 incubator & Bender (Germany) \\
19. & Loope & (Japan) \\
20. & Forceps & (Japan) \\
21. & Burner & (Japan) \\
\hline
\end{tabular}

\subsection{Chemical and Biological Materials}

Table 2. Chemicals and biological materials.

\begin{tabular}{lll}
\hline No. & Name & Company (Origin) \\
\hline 1. & Acetone & BDH \\
2. & Absolute ethyl alcohol & BDH (England) \\
3. & Absolute methyl alcohol & BDH \\
4. & Agar & Mast (England) \\
5. & Ap2oE & BDH \\
6. & Benedict & BDH \\
7. & Barium chloride (Bacl) & BDH \\
8. & Ehrlich's & BDH \\
9. & 5-Salfa Celiselic acid & BDH \\
10. & catlatse & BDH \\
11. & Oxidas & BDH \\
12. & Urea's & BDH \\
13. & Indol & BDH \\
14. & Voges Proskauer & BDH \\
15. & Normal Physiological salin & China \\
16. & Fushius & Fluka \\
17. & Sodium Chloride $($ Nacl $)$ & Fluka \\
18. & Sodium hydroxide & BDH \\
19. & Urea & BDH \\
20. & Ioden & Fluka \\
21. & Iodine Crystals & Fluka \\
22. & Phenol Crystals & Fluka \\
23. & Methyl red & Fluka \\
24. & Concentration acetic acid $(\mathrm{CH} 3 \mathrm{CooH})$ & Fluka (Germany) \\
25. & Urine Strips & Japan \\
\hline
\end{tabular}

\subsection{Stains}

Table 3. Stains.

\begin{tabular}{lll}
\hline No. & Name of Stain & Company (Origin) \\
\hline 1. & Crystal Violet & Fluka \\
2. & Methylene blue & Fluka \\
3. & Safranine & Fluka \\
4. & Basic Fuchsine & Fluka \\
5. & Strong Grobol Fuchsine & Fluka \\
\hline
\end{tabular}

\subsection{Serum and Kits}

Table 4. Serum and Kits.

\begin{tabular}{lll}
\hline No. & name & Company \\
\hline 1. & Urea Kit & Biomerinx (France) \\
2. & Creatinine Kit & Biomerinx (France) \\
\hline
\end{tabular}

\subsection{Antibiotics}

Table 5. Antibiotics Discs.

\begin{tabular}{|c|c|c|c|c|}
\hline No. & Name & Symbol & $\begin{array}{l}\text { Ab Concentration } \\
\mathrm{Mg} / \mathrm{disc}\end{array}$ & $\begin{array}{l}\text { Company } \\
\text { (Origin) }\end{array}$ \\
\hline 1. & Amoxicillin & Amx & $2 \mathrm{~S}$ & $\begin{array}{l}\text { Oxiod } \\
\text { (England) }\end{array}$ \\
\hline 2. & Ampicillin & $\mathrm{Am}$ & 10 & Oxoid \\
\hline 3. & Augmentin & Ac & 30 & Oxoid \\
\hline 4. & Cefixime & CFM & $\mathrm{S}$ & Oxoid \\
\hline 5. & Ceftriaxone & $\mathrm{CRO}$ & 30 & Oxoid \\
\hline 6. & Cephoxilin & $\mathrm{CN}$ & 30 & Oxoid \\
\hline 7. & Chloramphenicol & $\mathrm{C}$ & 30 & Oxoid \\
\hline 8. & Ciprofloxacin & $\mathrm{CF}$ & $\mathrm{S}$ & Oxoid \\
\hline 9. & Clindamycin & $\mathrm{CM}$ & 2 & Oxoid \\
\hline 10. & Cloxacillin & $\mathrm{CX}$ & $\mathrm{S}$ & Oxoid \\
\hline 11. & Doxycycline & DO & 30 & Oxoid \\
\hline 12. & Gentamycin & GM & 10 & Oxoid \\
\hline 13. & Lincomycin & $\mathrm{L}$ & $1 \mathrm{~S}$ & Oxoid \\
\hline 14. & Nalixic acid & NA & 30 & Oxoid \\
\hline 15. & Norfloxacin & $\mathrm{NX}$ & 10 & Oxoid \\
\hline 16. & Peincillin G & $\mathrm{P}$ & $10 \mathrm{i} 4$ & Oxoid \\
\hline 17. & Piperacllin & $\mathrm{PC}$ & 100 & Oxoid \\
\hline 18. & Rifampicin & $\mathrm{RD}$ & 30 & Oxoid \\
\hline 19. & Strepytomycin & $\mathrm{S}$ & 10 & Oxoid \\
\hline 20. & Tetracyclin & $\mathrm{Te}$ & 30 & Oxoid \\
\hline 21. & Trimetheprim & TR & $2 \mathrm{~S}$ & Oxoid \\
\hline 22. & Vancomycin & VA & 30 & Oxoid \\
\hline 23. & Amikacin & $\mathrm{AK}$ & 10 & Oxoid \\
\hline 24. & Tobramycin & $\mathrm{Tb}$ & 30 & Oxoid \\
\hline 25. & Cephalexin & CFA & 10 & Oxoid \\
\hline
\end{tabular}

\subsection{Culture Media}

Table 6. Culture media.

\begin{tabular}{lll}
\hline No. & Name of medium & Company (Origin) \\
\hline 1. & Macconkey & Himedia (India) \\
2. & Trypticase Soy broth & Himedia (India) \\
3. & Nutrient agar & Himedia (India) \\
4. & Blood agar & Himedia (India) \\
5. & Mueller Hinton agar & Himedia (India) \\
\hline
\end{tabular}

All culture media were prepared according to information of manufacturing company. 


\subsection{Prepared Media}

Table 7. Prepared media.

\begin{tabular}{ll}
\hline No. & Name of Medium \\
\hline 1. & Hydrogen Sulphide production Medium \\
2. & Indole test medium (peptone water) \\
3. & Methyl redanf voges-proskauer test medium \\
4. & Urea agar (Christense medium) \\
\hline
\end{tabular}

\section{Results}

These study included (230) patients suffered from urinary tract infections with or without renal failure from Al-zahraa and Al-Karama teaching hospital in Wassit governorate in period from October 2009 to October 2010 in age between (2-70) years old in different gender, urine and blood samples was collected from them,

after culturing of all urine samples on different media the results showed that 194

(84.3\%) gave positive result compared with 36 (15.7\%) negative, the blood samples used for detecting creatinine, urea and also fasting blood sugar was done to them, the results who were detected recorded in Table 8 below:

Table 8. Numbers and types of bacterial pathogens in which isolated from patient with urinary tract infections with or without renal failure.

\begin{tabular}{lllll}
\hline \multirow{2}{*}{ Age } & \multicolumn{2}{l}{ Name of bacteria } & \multirow{2}{*}{ Number of infection } \\
\cline { 2 - 4 } & $\boldsymbol{E}$. coli & Proteus & Klebsiella & \\
\hline 2-15 years & $30(83 \%)$ & $2(5.5 \%)$ & $1(2.7 \%)$ & 36 \\
16-40 years & $36(32.4 \%)$ & $26(23.4 \%)$ & $20(18 \%)$ & 111 \\
41-70 years & $17(20.4 \%)$ & $30(36.1 \%)$ & $21(25.3 \%)$ & 83 \\
\hline
\end{tabular}

Results of this study accepted with (Kolen, 1986 ) 89.5\% and (Hamlemant, 1990) that show infection 87\%, (Baka'ss, 1995 ) that show infection $80 \%$ and (Alataboy, 1999) that show infection $83 \%$, also thes study show high percentage from the result (Haekal, 2001) that show the infection 70\% and (Sadk Alaalak, 2003 )that show infection 65\% from 311 urine samples.

In addition to that this study show low percentage from the results of (Jabir Alhashimy, 2005) that show infection 91\% from patients with or without renal failure gave positive results.

\subsection{Blood Urea and Serum Creatinine}

Blood urea and serum creatinine tests was done to 222 patients in which suffered from urinary tract infections, the results showed 94 (42.3\%) patients with different age and sex suffered from renal failure.

Also showed that patient suffering from renal failure in age between (2-15) years old was 4 (4.2\%) patients, (16-40) years old was $20(21.2 \%)$ and (41-70) years old was 70 (74.4\%) patients.

This result was accepted with following results Mohamad Alataby, 1993 in which obtained 40\% renal failure from 200 blood samples, Mazin Alsalmmyu, 2005 that show 41\% renal failure from 210 blood samples and Abd Alfetah Alraawy, 2008 that show $40 \%$ renal failure from 195 blood samples also these study show high percentage from Alataby, 2006 $30 \%$ renal failure from 250 blood samples and Mar hamtim, 2007 that show 31\% renal failure from 260 blood samples, also this results different from Albayty and Marhomtin, 2002 but this result of last two researcher builded on samples collected from patients with aged between (1-20) years old bit this study collection blood samples between (2-70) years old.

\subsection{Biochemical Tests}

The biochemical were used to confirm identification of different bacteria isolate these test include (catalase, oxidase, unease, Indole, methyl, voges-porskouer- siammon citrate, $\mathrm{H} 2 \mathrm{~S})$ tests.

Results of this tests for $E$. coli bacteria positive for catalase, indole, methyl red and negative to oxidase, simmon citrate and vogas-postkawer test, also kelbsiella gave positive to catalase, siammon citrate, vogas- proskowres and negative to oxidase, indol and methyl red and also proteus gave the following result Table (9):

Table 9. Biochemical tests for different bacteria isolated from culture of human urine.

\begin{tabular}{|c|c|c|c|c|c|c|c|c|}
\hline Name of bacteria isolate & Catalese & Oxidese & indole & urease & Methyl red & Voges proshouer & Simmon citrate & Hydrogen Sulfide production \\
\hline E. coli & + & - & + & - & + & - & - & - \\
\hline Klebsiella & + & - & - & - & - & + & + & - \\
\hline Proteus & + & - & + & + & + & - & - & - \\
\hline
\end{tabular}

\subsection{Sensitivity Test}

The results of antibiotics sensitivity test to most common bacterial pathogens in which isolated in this study appeared in following table:

Table 10. Antibiotics sensitivity test for common pathogens isolated from renal failure and urinary tract infection patients.

\begin{tabular}{|c|c|c|c|c|c|c|}
\hline \multirow{2}{*}{ Antibiotic name } & \multicolumn{2}{|l|}{ E. coli } & \multicolumn{2}{|l|}{ Klebsiella } & \multicolumn{2}{|l|}{ Proteus } \\
\hline & Senstivity\% & Resistance\% & Senstivity\% & Resistance\% & Senstivity $\%$ & Resistance\% \\
\hline ampicillin & $91 \%$ & 9 & $68 \%$ & $32 \%$ & $100 \%$ & 0 \\
\hline Cefixime & $91 \%$ & 9 & $100 \%$ & 0 & $93 \%$ & $6.8 \%$ \\
\hline Ceftriaxone & $93 \%$ & 7 & $100 \%$ & 0 & $100 \%$ & 0 \\
\hline Cephoxilin & $97 \%$ & 3 & $100 \%$ & 0 & $63.7 \%$ & $36.3 \%$ \\
\hline Chloramphenicol & $96 \%$ & 4 & $78.7 \%$ & $21.2 \%$ & $91.3 \%$ & $8.6 \%$ \\
\hline
\end{tabular}




\begin{tabular}{|c|c|c|c|c|c|c|}
\hline \multirow{2}{*}{ Antibiotic name } & \multicolumn{2}{|l|}{ E. coli } & \multicolumn{2}{|l|}{ Klebsiella } & \multicolumn{2}{|l|}{ Proteus } \\
\hline & Senstivity\% & Resistance\% & Senstivity\% & Resistance\% & Senstivity\% & Resistance\% \\
\hline Ciprofloxacin & $91 \%$ & 9 & $78.7 \%$ & $21.2 \%$ & $86.2 \%$ & $13.7 \%$ \\
\hline Clindamycin & $91 \%$ & 9 & $65.8 \%$ & $34 \%$ & $96.5 \%$ & $3.4 \%$ \\
\hline Cloxacillin & $91 \%$ & 9 & $97.8 \%$ & $2.1 \%$ & $100 \%$ & 0 \\
\hline Doxycycline & $92 \%$ & 8 & $100 \%$ & 0 & $89.6 \%$ & $10.4 \%$ \\
\hline Gentamycin & $87 \%$ & 13 & $100 \%$ & 0 & $74.1 \%$ & $25.8 \%$ \\
\hline Lincomycin & $88.8 \%$ & 11.2 & $68 \%$ & $31.9 \%$ & $100 \%$ & 0 \\
\hline Nalixic acid & $82 \%$ & 18 & $85.1 \%$ & $1.4 \%$ & $91.3 \%$ & $8.6 \%$ \\
\hline Norfloxacin & $91 \%$ & 9 & $91.4 \%$ & $8.5 \%$ & $94.8 \%$ & $5.1 \%$ \\
\hline Peincillin G & $69 \%$ & 31 & $95.7 \%$ & $4.5 \%$ & $98.2 \%$ & $1.7 \%$ \\
\hline Piperacllin & $88 \%$ & 12 & $100 \%$ & 0 & $98.2 \%$ & $1.7 \%$ \\
\hline Rifampicin & $22.2 \%$ & 77.8 & $100 \%$ & 0 & $100 \%$ & 0 \\
\hline Strepytomycin & $66.6 \%$ & 33.4 & $100 \%$ & 0 & $98.2 \%$ & $1.7 \%$ \\
\hline Tetracyclin & $77.7 \%$ & 32.3 & $89.3 \%$ & $1.4 \%$ & $81.1 \%$. & $18.9 \%$ \\
\hline Trimetheprim & $88.8 \%$ & 11.2 & $87.2 \%$ & $12.7 \%$ & $100 \%$ & 0 \\
\hline Vancomycin & $91 \%$ & 9 & $100 \%$ & 0 & $100 \%$ & 0 \\
\hline Amikacin & $91 \%$ & 9 & $87.2 \%$ & $12.7 \%$ & $84.4 \%$ & $15.5 \%$ \\
\hline Tobramycin & $92 \%$ & 8 & $100 \%$ & 0 & $82.7 \%$ & $17.2 \%$ \\
\hline Cephalexin & $98 \%$ & 2 & $100 \%$ & 0 & $100 \%$ & 0 \\
\hline Amoxicillin & $66.6 \%$ & 33.4 & $76.5 \%$ & $23.4 \%$ & $55.1 \%$ & $44.85 \%$ \\
\hline
\end{tabular}
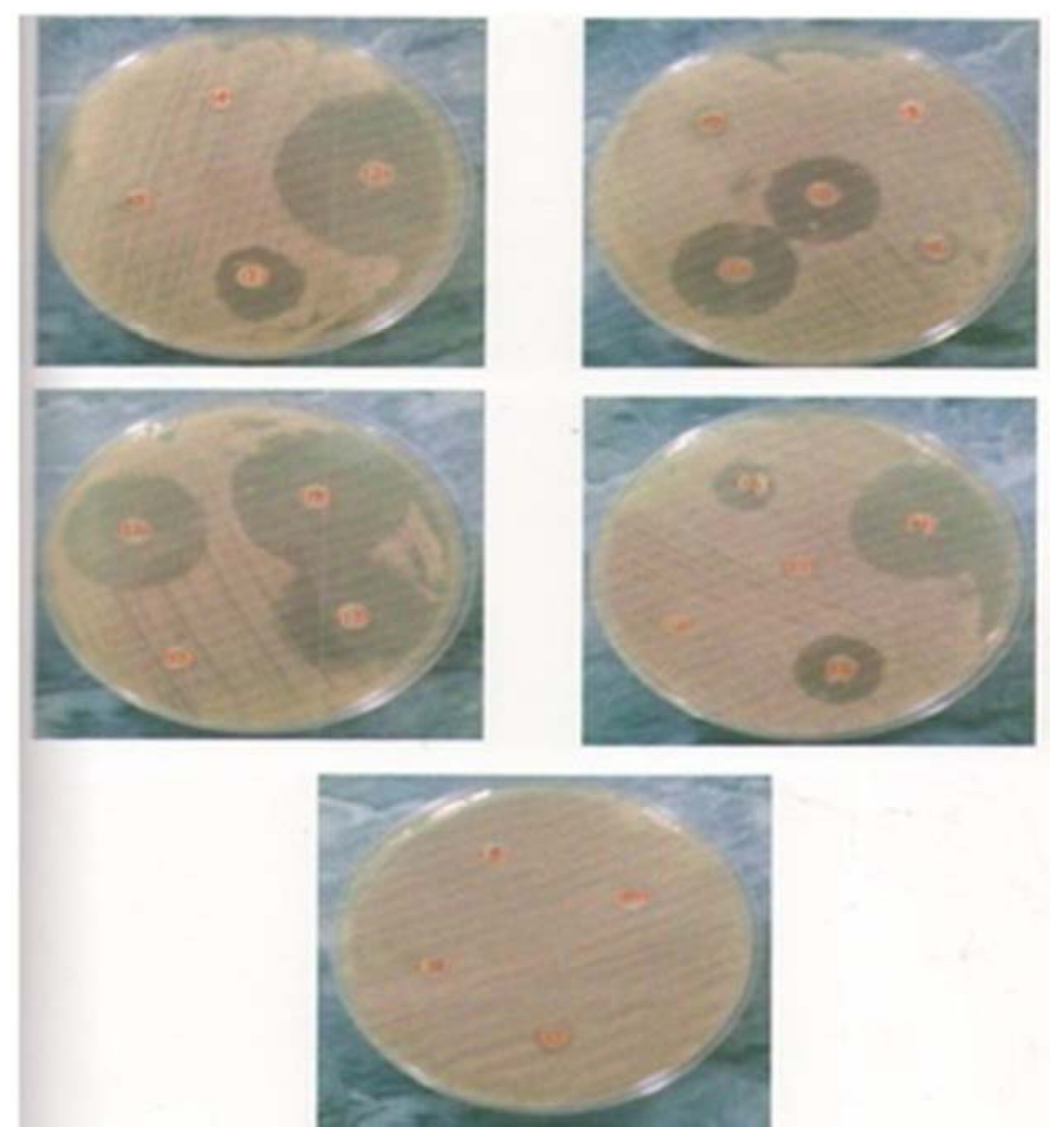

Figure 1. Sensitivity test to patients with renal failure and or without urinary tract.

\subsection{Follow up After Treatment}

\subsubsection{General Urine Examination (GUE)}

After treatment the patients follow up by this test and also by sensitivity test using 25 antibiotic (Table 10) in which show:

It's the percentage of recovered $77.4 \%$, and $22.5 \%$ patients non recovered from urinary tract infections with or without renal failure.

Table 11. Numbers and percentages of patients which was suffered from UTIs and diabetic and also recovered patients.

\begin{tabular}{lll}
\hline Total number of patients & Suffered from UTI and diabetic & Recovered from UTIs after treatment \\
\hline 230 & $71(31.9 \%)$ & $172(77.4 \%)$ \\
\hline
\end{tabular}




\subsubsection{Blood Urea and Serum Creatinine}

After treated of patient retest of blood urea and serum creatinine by take blood samples from the patients, the results of this testes showed the percentage of recovered patients from renal failure $45(47.8 \%)$ from 94 , ratio of treated renal failure at aged between (2-15) years old $100 \%$, aged, between (16-40)years old $71.8 \%$ and $33.3 \%$. in age group between 41 to 70 years old. This results was agreed with (kovien, 2003), in which show 38\% of renal failure was recovered after treatment, (Kadear Alwan, 2005) 50\% renal failure also agreed with result of Haider Abid Alkalik, 2007 (35\%), and (Kalid ali, 2004) that show 30\%. But it high from results obtained by Walees Amer, 2004 in which $25 \%$.

Also noted that all patients suffered from renal failure had urinary tract infections but very low numbers had firstly urinary tract infections them infected with renal failure for this case appeared that renal failure enhanced ability to grow different bacteria them can lead to infected with urinary tract infections.

\section{Conclusion}

According to our study and results achieved we can conclude the following:

1. The result of this study shows found most 3 types of bacteria in which caused of urinary tract infection $(E$. Coli, Klebsiella and proteus).

2. The result of this study shows its high number at patient that age between (41-70) years old suffering from renal failure.

3. The result at this study shows it high number at patient that have suffering from renal failure that have suffering from urinary tract infection.

4. The result of this study shows it's the percent of covered to patient that have suffering from renal failure and urinary tract infection low from percent of covered to patient that had suffering from urinary tract infection only.

5. The results of this study shows it's all types of bacteria caused urinary tract infection sensitive to many antibiotic

6. The results of this study shows it's all type at bacteria caused urinary tract infection resistance to some antibiotics.

7. The result of this study shows its high number of individual that live in village and poor that had urinary tract infections more than percent the individual that live in center city and rich man.

8. The result of this study showed that E. Coli bacteria found in large number in age between 2-15 years old.

9. The results of this study showed high number of patient that suffering from diabetic metallic and urinary tract infections.

\section{References}

[1] Abbott, S. L., O'Connor, J., Robin, T. et at. (2003) "Biochemical Properties of a newly described Escherichia species, Eschcrichia albertii." Journal of Clinical Microbiology 41: 4852-4854.

[2] Agace, W., Hedges, S., Andersson, U. et at. (1993) "Selective cytokine production by epithelial cells following exposure to Escherichia coll." Infection and Immunity 6\ 602-609.

[3] Al Mamun, A. A. M., Tominaga, A. and Enomoto, M. (1996) "Detection and characterization of the flagellar master operon in the four Shigella subgroups." Journal of Bacteriology 178: 3722-3726.

[4] Ashkenazi, S., Levy, I., Kazaronovski, V. and Samara, Z. (2016) "Growing antimicrobial resistance of Shigella isolates." The Journal of Antimicrobial Chemotherapy 51: 427-429.

[5] Azad, M. A., Islam, M. and Butler, T. (1986) "Colonic perforation in Shigella dysenteries 1 infection." The Pediatric Infectious Disease Journal 1: 103-104.

[6] Kolen, F. (1986) "Uropathogenic Escherichia coli." In Escherichia colt: Virulence Mechanisms of a Versatile Pathogen. M. S. Donnenberg (ed.). London Academic Press, 239-268.

[7] Hamlemant, B. (1990) "A sensitive and specific DNA probe to identify enter aggregative Escherichia coli, a recently discovered diarrhea pathogen." The Journal of Infectious Diseases 161: 1249-1251.

[8] Baka'ss, M. (1995) "Characterization of an RTX toxin from enter hemorrhagic Escherichia coli 0157:H7." Infection and Immunity 64:167-175.

[9] Alataboy, M. L. (1996) "Mortality due to shigellosis: community and hospital data." Reviews of Infectious Diseases 13 (Suppl. 4): S219-S224.

[10] Haekal, M. L. (2001) "Rethinking options for the treatment of shigellosis." The Journal of Antimicrobial Chemotherapy 30: 243-247.

[11] Sadk Alaalak. (2003) "Identification of Ics A, a plasmid locus of Shebelle Flexner that governs bacterial intra- an intercellular spread through interaction with F-acting." Proceeding of the National Academy of Sciences of the United States of America 86: 3867-3871.

[12] Jabir Alhashimy. (2005) 'The Afa/Dr adhesins of diffusely adhering Escherichia coli stimulate interleukin-8 secretion, activate mutagen-activated protein kinesis, and promote polymorph nuclear Tran epithelial migration in T84 polarized epithelial cells." Infection and Immunity 71: 1068-1074.

[13] Mohamad Alataby, (1993) "Reliability of CHROMagar O157 for the detection of entero hemorrhagic Escherichia coli (EHEC) 0157 but not EHEC belonging to other serigraphs." Journal of Applied Microbiology 85: 425-428.

[14] Mazin Alsalmmyu. (2005) "Rapid laboratory identification and characterization of verify tot oxygenize (shiga toxin producing) Escherichia coli (VTEC/STEC)." Journal of Applied Microbiology 95:205-217. 
[15] Alfetah Alraawy. (2008) "The different hemolysins of Escherichia call." Medical Microbiology and Immunology 180: 167-182. Beutin, L. (1999) "Escherichia coli as a pathogen in dogs and cats." Veterinary Research: 285-298.

[16] Alataby. (2006) "Close association of era toxin (Shiga-like toxin) production with enter hemolytic production in strains of Escherichia coli." Journal of Clinical Microbiology 27: 25592564.

[17] Mar hamtim. (2007) "An evaluation of current shigellosis treatment." Expert Opinion on Pharmacotherapy 4: 1315-1320.

[18] Albayty and Marhomtin (2002). "Molecular characterization of a fibril adhesion, Fl 845, mediating diffuse adherence of diarrhea-associated Escherichia coli to HEp-2 cells." Journal of Bacteriology 171:4281289.

[19] Abd Alfetah Alraawy. (2008). "Epidemiology of verocytotoxigenic Escherichia coli (VTEC) in ruminants." In Veracity oxygenic E. coli. G. Duffy, P. Garvey and D. A. McDowell (ed. s). Trumbull, CT: Food \& Nutrition Press, 113-148.

[20] kovien. (2003) "Enter pathogenic Escherichia coli." in Escherichia coli: Virulence Mechanisms of Versatile Pathogen. M. S. Dannenberg (ed.). London: Academic Press, 81-118.
[21] Kadear Alwan. (2005). Plunkett, G., Bloch, C. A. et al. (1997) "The complete genome sequence of Escherichia coli K12." Science 277: 1453-1474.

[22] Haider Abid Alkalik. (2007)."The tripartite type III secreton of Shigella flexneri inserts $\mathrm{IpaB}$ and $\mathrm{IpaC}$ into host membranes."The Journal of Cell Biology 147: 683-693.

[23] Kalid ali, (2004). "Binding of the Shebelle protein IpaA to vinculum induces F-acting de polymerization." The EMBO Journal 18: 5853-5862.

[24] Brenner, D. J., Fanning, G. R., Johnson, K. E. et at.. (1969) "Polynucleotide sequence relationships among members of Nitrobacteria cease." Journal of Bacteriology 98: 637-650.

[25] Walees Amer. (2004), R., Acar, G. et at.. (2003) "Identification and characterization of a new variant of Shiga toxin 1 in Escherichia coli ON'f:H19 of bovine origin." Journal of Clinical Microbiology 41: 2106-2112. 